\title{
Field tests of components regenerated using the MULTIPLEX technology
}

\author{
L. Klimek, A. Krasiński, E. Wołowiec-Korecka * \\ Institute of Material Science and Engineering, Lodz University of Technology, \\ ul. Stefanowskiego 1/15, 90-924 Łódź, Poland \\ * Corresponding e-mail address: emilia.wolowiec@p.lodz.pl
}

\section{ABSTRACT}

Purpose: The purpose was to show the results of the field tests of components carried out using the MULTIPLEX technology.

Design/methodology/approach: The field tests have been carried out on the following components: brake expanders of Mercedes bus, a pintle of the tram trolley component, a pin from a casting cleaning plant element. Each of the tested elements was subject to regeneration through steel surfacing by welding and then chemical and heat treatment. The regenerated elements were compared with original ones working at the same service conditions.

Findings: The findings have shown significant prolongation of life of the components regenerated using the MULTIPLEX technology in relation to the original components.

Research limitations/implications: The shown regeneration technology is the cost effective way to restore the suitable performance traits or to ensure preventively the suitable properties by initial protection of newly manufactured elements or regeneration of old ones within the framework of recovery procedure.

Originality/value: The shown regeneration method is the advanced technology combining welding with chemical and heat treatment.

Keywords: Regeneration; Machine components; Surfacing by welding; Chemical and heat treatment

\section{Reference to this paper should be given in the following way:}

L. Klimek, A. Krasiński, E. Wołowiec-Korecka, Field tests of components regenerated using the MULTIPLEX technology, Journal of Achievements in Materials and Manufacturing Engineering 78/2 (2016) 59-64.

\section{MANUFAGTURING AND PROGESSING}

\section{Introduction}

At the present state of technology, reliability and life of machines, devices and tools is of vital importance. Intensive operation of machine and device parts results in increase of wear and tear of mating elements and this, in effect, can lead to their failure. Increase of requirements for operational parameters of machine parts due to, in particular, heavy load, high speed, wide range of temperatures and aggressive environment, results in the accelerated wear and tear and sometimes leads to destruction of whole components. These processes occur or are initiated mostly in the surface layer zone. Thus, the basic operational features of a machine, a device or a tool 
depend mainly on their surface layer properties. Therefore, the most effective method of their performance improvement is formation of this layer structure and chemical properties [1].

Regeneration is used to restore suitable structural features and performance of damaged or worn parts. It can be carried out be means of different methods. At present, many methods of regeneration are available including welding, galvanic and structural methods, plastic working, etc. The methods of regeneration are substantially adaptations of technologies used in the process of new elements manufacturing.

The performance, technical and economic criteria decide chiefly on choice of the regeneration technology. Among many factors specifying the criteria, the most noteworthy are these that decide on the applied layer quality and costs; their optimization underlies the solution of the machine and device regeneration question.

The cost effective way to restore the suitable performance traits or to ensure preventively the suitable properties is initial protection of newly manufactured elements or regeneration of old ones within the framework of recovery procedure by coating.

At present, welding is used more and more often [2]. Surfacing by welding allows forming of the surface layer and optimization of machine and device performance. Wear of elements in shape of geometric losses is more intensive than their fatigue wear; therefore, the surfacing by welding is used as a method of reconstruction of the worn part dimensions and as a method of forming of the surface layer properties (eg. as a result of surfacing by hardening welding provided within the processing) to obtain padding welds of required chemical composition, strength and hardness [3]. Use of surfacing by welding to regenerate fast wearing out parts is the source of great material savings. A thin layer of even very expensive material applied on a substrate of carbon or low-alloy steel can be cost effective considering the total mass of the element of big overall dimensions made often of alloy steel and prolongation of life of fast wearing out parts that is the source of not only material savings but also increase of effective use of the machine due to limitation of standstills as a result of lower frequency of worn part replacement $[4,5]$.

Hardened surface layers of different type are widespread at the contemporary mechanical engineering; they are obtained with heat treatment and heat and chemical treatment methods [1] Use of surfacing by welding combined with further upgrading of the surface layer by heat treatment and heat and chemical treatment can significantly increase life of elements [6-8] For economic purposes, it is very advantageous to carry out low-carbon/low-alloy and unalloyed padding welds and then process them using cheap, advanced methods of heat and chemical treatment, vacuum carburizing and gas sulfonitriding $[9,10]$. Suchlike regenerating technologies are called the multiplex technologies. The flow diagram of this regeneration method can be shown as follows:

\section{a regenerated element $\rightarrow$ analysis of wear nature and service conditions $\rightarrow$ \\ $\rightarrow$ choice of material and regeneration method $\rightarrow$ heat and chemical treatment}

The purpose of this study was to show the results of the field tests of components carried out using the MULTIPLEX technology.

\section{Materials and experiments}

The following components were chosen for the field tests:

a) brake expanders of Mercedes bus,

b) a pintle of the tram trolley component,

c) a pin from a casting cleaning plant element

A steel layer was padded onto each of the above components and then, after dimensional treatment, the heat and chemical treatment was used. For surfacing by welding, the automatic station for electro-vibration pad welding of rotational elements was used including argon and helium mixture as shielding gas.

\subsection{Brake expanders of Mercedes bus}

The field tests for the brake expanders were carried out on the components regenerated by single pad welding with constructional steel 41CrAlMo7 (38HMJ); after pad welding, their surfaces were ground and they were treated using gas sulfonitriding of the following parameters: process temperature $-570^{\circ} \mathrm{C}$, process time $6 \mathrm{~h}$ (Fig. 1).

So prepared components were mounted in the bus operated by the communication enterprise MPK Lodz. In the braking system of the bus under investigation, two types of expanders were mounted on the one axle - the regenerated one (on the left front wheel) and the original factory one (non the right front wheel). The bus was operated normally at one of the municipal transport services lines. After 12 months of operation and mileage $69,850 \mathrm{~km}$, all expanders were demounted and subjected to comparative macroscopic examinations.

The expanders after different stages of the field tests are shown in Figure 2. 
a)

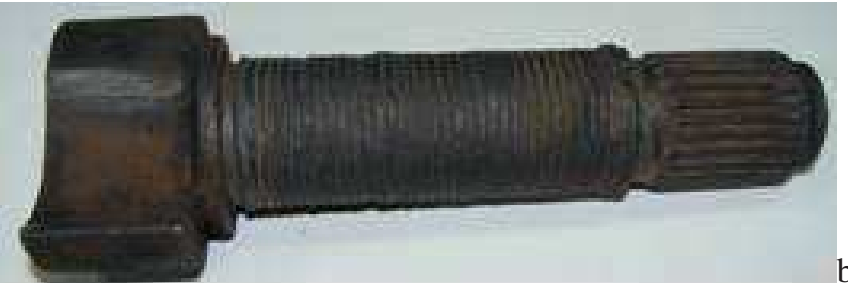

b)

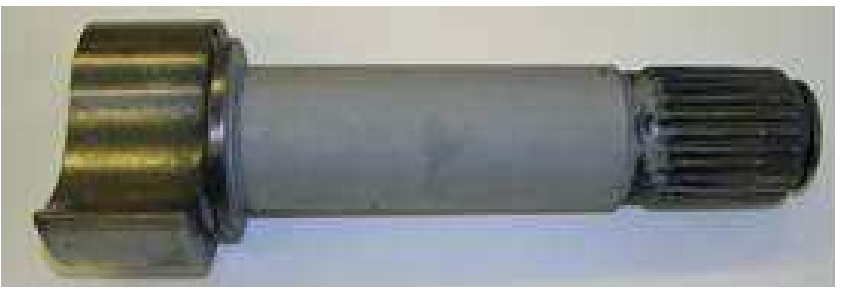

Fig. 1. Expander regeneration a) the expander after pad welding with steel 38 HMJ b) the ready expander - after pad welding, grounding and sulfonitriding

a)

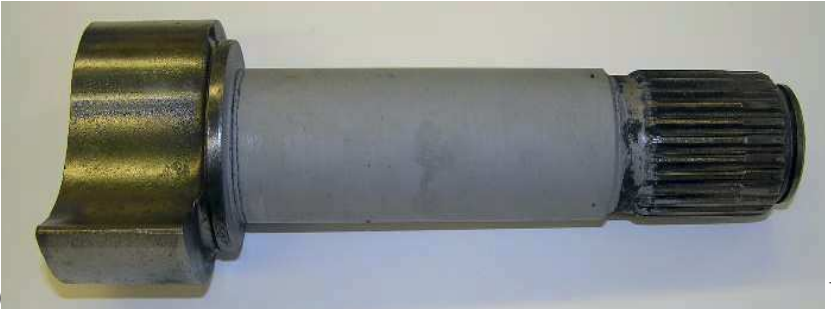

c)

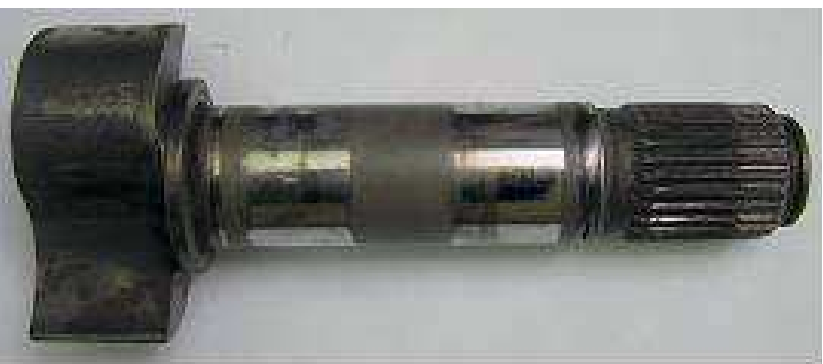

d)
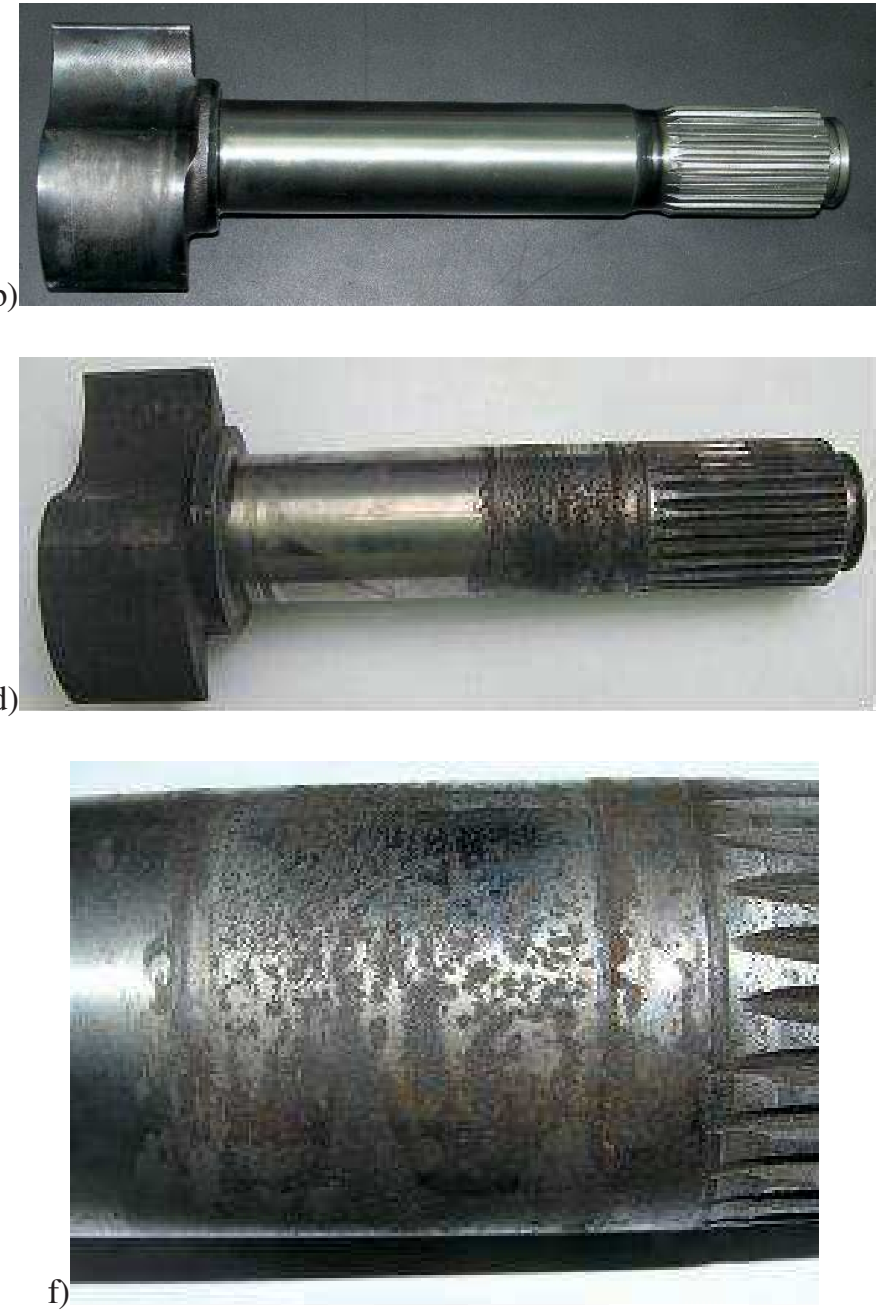

Fig. 2. Macroscopic images of the expander regenerated with multiplex technology (left column) and original one (right column): a),b) - expanders before installation in the bus, c),d) - expanders after 9 months of operation, e),f) - enlargement of the working surface located at the splines

Comparison of appearance of original expanders and these carried out using MULTIPLEX technology, operated at the same conditions and time, indicates that wear of the latter is significantly lower. While in original expanders after 9 months of operation, the significant wear can be seen in the shape of abraded grooves, the expanders carried out using MULTIPLEX technology show only brightening of the mating surfaces. 


\subsection{Pintle}

A pintle of the tram trolley component (Fig. 3 and Fig. 4) was chosen for tests. It was regenerated by pad welding with the material conforming to steel 13CrMo4-5 (15 HM) and then treated using gas sulfonitriding of the following parameters: process temperature $-570^{\circ} \mathrm{C}$, process time $6 \mathrm{~h}$. The view of the pintle before and after regeneration is shown in Figure 5.

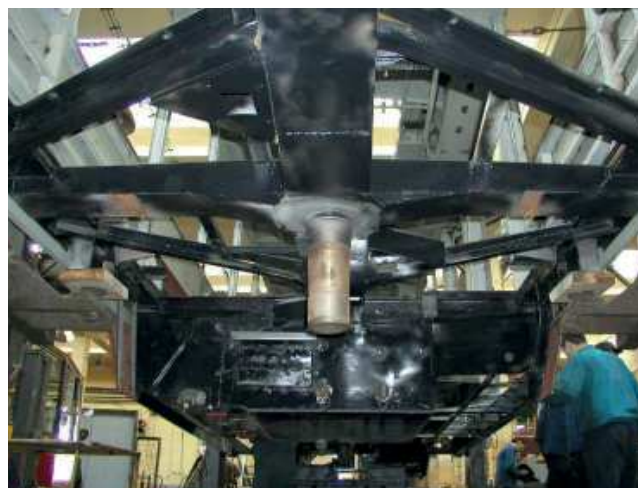

Fig. 3. A pintle of the tram trolley component
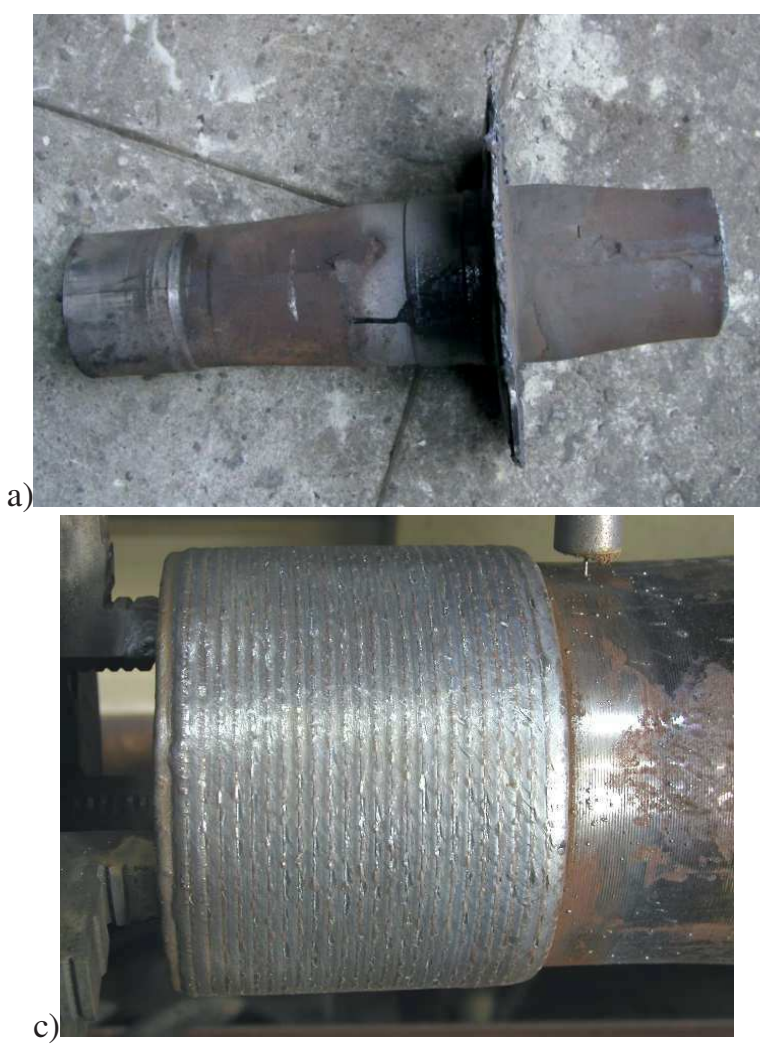

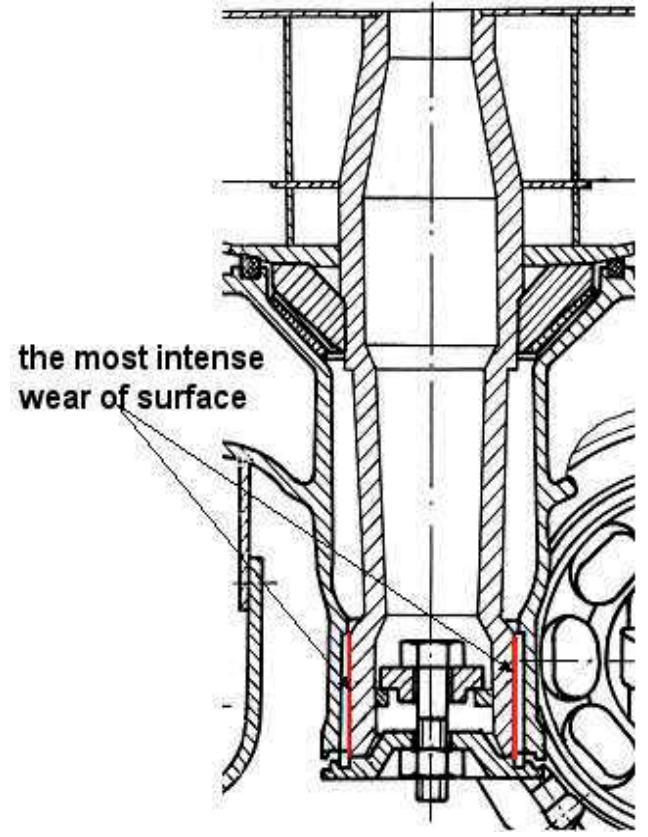

Fig. 4. A pintle of the tram trolley component - schematic view

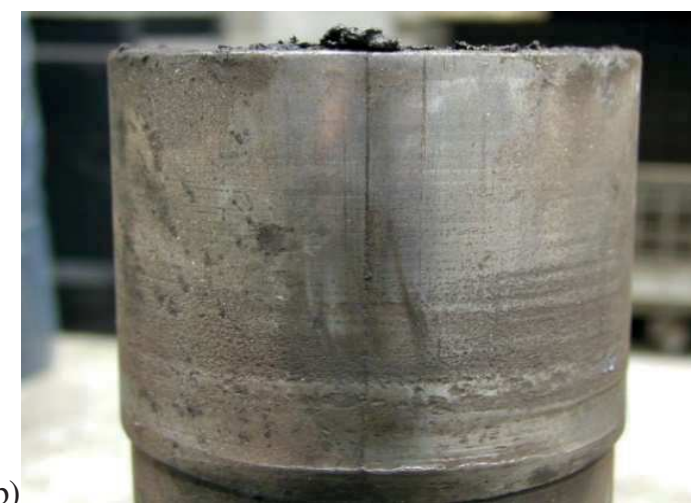

b)

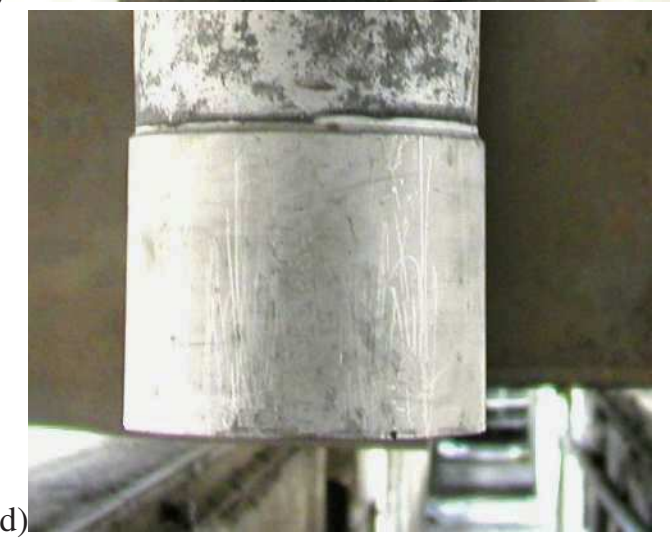

Fig. 5. The regenerated pintle of the tram trolley component: a) the demounted pintle, b) the worn pintle surface, c) the pintle surface after pad welding, d) the pintle surface after pad welding and gas sulfonitriding 
After regeneration using MULTIPLEX method, the pintle was fastened in the street car operated within one of the traffic routes of collective transport system in the area of Łódz. After one-year operation and mileage about $70,000 \mathrm{~km}$, a visual inspection of the regenerated surface of the pintle was carried out. The view of the pintle after the field tests is show in Figure 6.

Improvement of properties of the surface layer of the tested pintle after regeneration using MULTIPLEX method can be evidenced by wear of the regenerated pintle and the unregenerated one shown in Figure 7, after the same operating period.

No marks of wear or damage were found on the regenerated pintle surfaces. The thin external sulfurizing

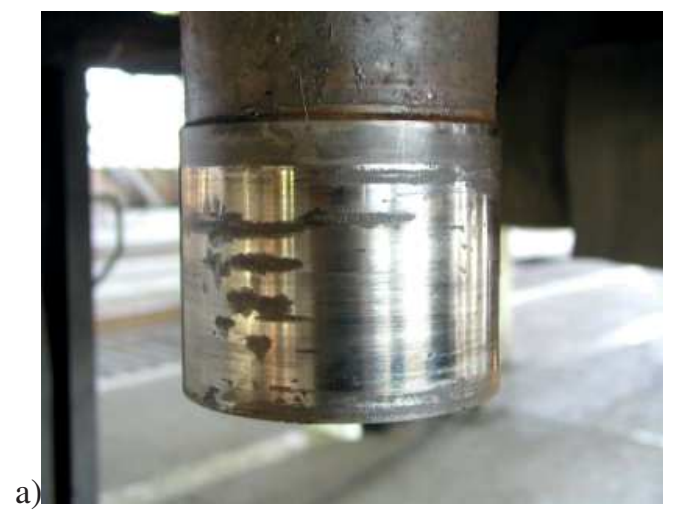

zone obtained during the heat and chemical treatment has not been even spread completely during the pintle and sleeve running-in within the initial operating period.

\subsection{Pin of a casting cleaning plant}

A pin from a casting cleaning plant element is the next component under test. Its regeneration consisted in pad welding with the material of composition conforming to composition of high-speed steel HS 6-5-2 (SW7M) and then vacuum nitriding.

Fig. 8 shows the pin before regeneration (after 300 hours of operation in the cleaning plant element) and the regenerated pin (after 1,818 hours of operation).

Fig. 6. The pintle surface after mileage about $70,000 \mathrm{~km}$ a) the original pintle, b) the pintle regenerated using MULTIPLEX technology
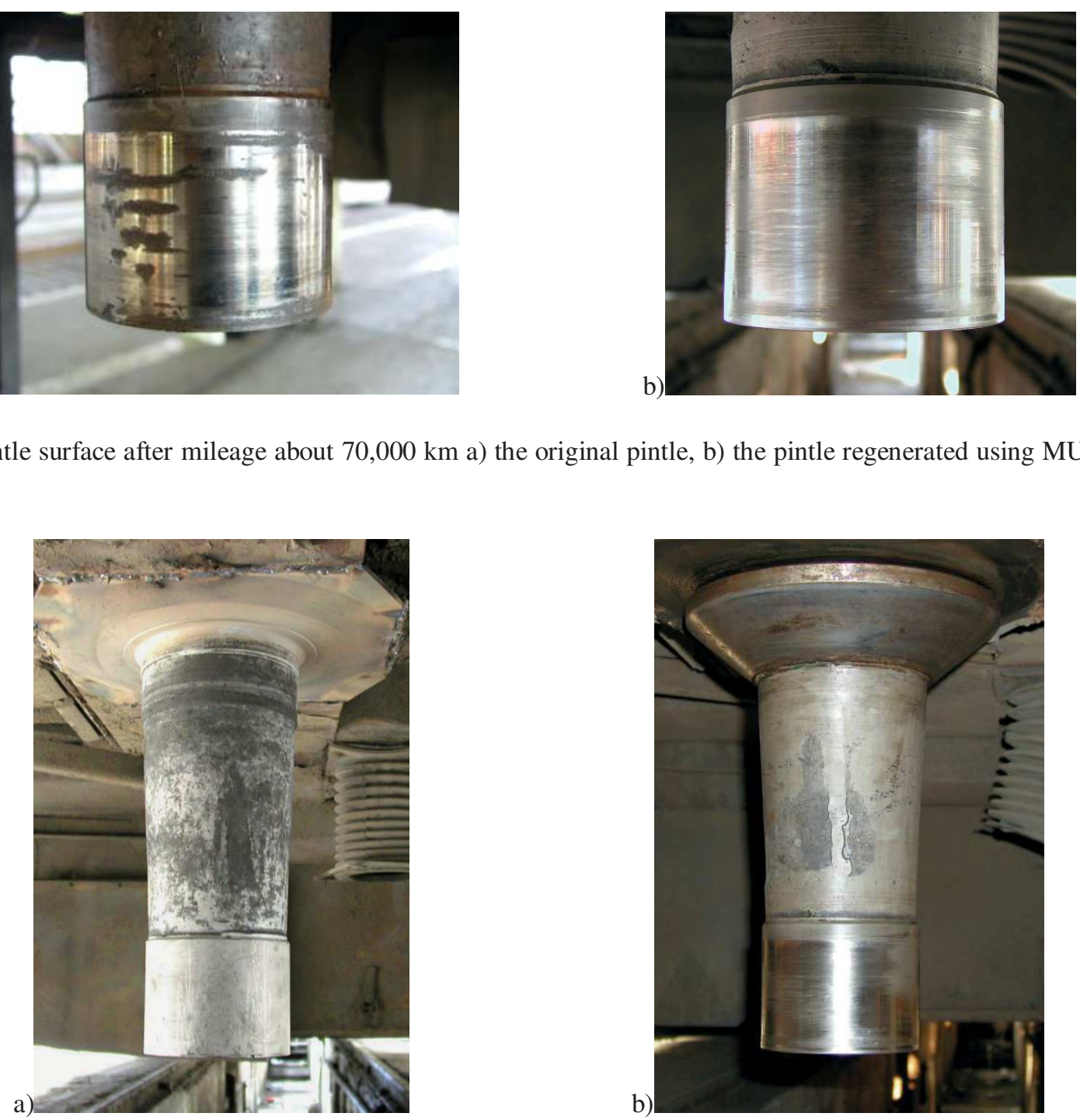

Fig. 7. The pintle view: a) the pintle prepared for tests b) the pintle after regeneration tests 
a)

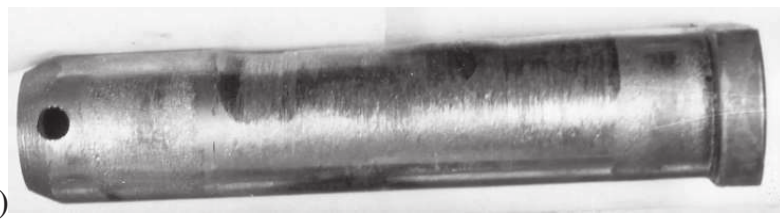

b)

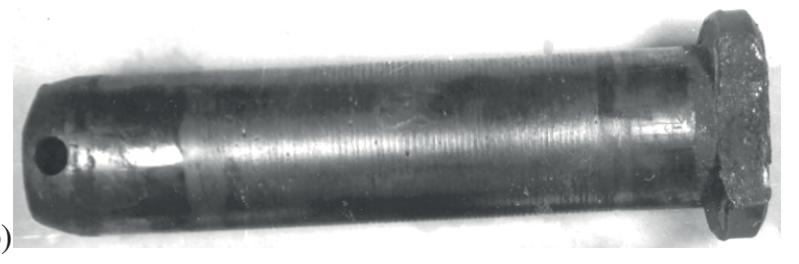

Fig. 8. The surface of the pin from a casting cleaning plant element: a) the pin before regeneration (300 hours of operation), b) the pin after regeneration (1818 hours of operation)

It can be seen in the figures shown that in spite of six times longer time of operation, the pin regenerated using MULTIPLEX technology shows practically no wear as compared with the original pin where significant wear on its surface can be seen clearly.

The presented examples prove correctness of the planned and carried out regeneration of selected components. Using the presented MULTIPLEX technology, steels of different type can be pad welded and subjected to different heat and chemical treatments. The similar tests carried out before by the authors of this study on guide and skinning rolls of a drawing machine [11,12] have also shown significant extension of life of the components regenerated using MULTIOLEX technology in relation to the original ones.

\section{Conclusions}

The results of the presented tests allow to find that:

1. The life of the components regenerated using MULTIOLEX technology is longer than the life of the original ones.
2. This technology can be used for both regeneration and manufacture of new components.

\section{References}

[1] P. Kula, Surface layer engineering, Monograph, PŁ, 2000 (in Polish).

[2] A. Klimpel, Welding and thermal spraying, WNT, Warsaw, 2000 (in Polish).

[3] W. Wojciechowski, Rating the quality of surfacing on the basis of abrasion resistance. $37^{\text {th }}$ Conference Industrial applications of welding technologies. Częstochowa - Poraj, 1994, 185-192 (in Polish).

[4] P. Adamiec, J. Dziubiński, Testing and modeling of wear of surfaced machine parts wear, Overview Welding 1/2 (1996) 3-6 (in Polish).

[5] P. Adamiec, J. Dziubiński, Modeling of wear surfaced layers, Proceedings of Regeneration '95 Conference, Bydgoszcz, 1995, 7-12 (in Polish).

[6] Z. Haś, J. Kaczmarek, Vacuum nitriding of surfaced layers on steel PN45, Proceedings of $3^{\text {rd }}$ Scientific Conference Surface Treatment, Częstochowa - Kule, 1996, 91-95 (in Polish).

[7] A. Krasiński, Regeneration of machine parts by surfacing low-carbon low-alloy steel with thermochemical treatment after welding, PhD Thesis, Lodz University of Technology, Lodz, 2003 (in Polish).

[8] J. Kaczmarek, Applying a layer of high hardness by surfacing, PhD thesis, Lodz University of Technology (in Polish).

[9] A. Krasiński, L. Klimek, P. Kula, Tests of resistance to scuffing layer of regeneration obtained by MULTIPLEX, Tribology 4 (2005) 113-120 (in Polish).

[10] A. Krasiński, L. Klimek, J. Kaczmarek, Regeneration of machine parts using MULTIPLEX technology. Proceedings of $5^{\text {th }}$ Conference, Materiałografia 2005, Puck, 2005, 35-44 (in Polish).

[11] A. Krasiński, L. Klimek, The Multiplex technology to rollers, Surface Engineering 2 (2006) 73-76 (in Polish). 